\title{
A GESTÁO DA QUALIDADE EM FABRICANTES DE EQUIPAMENTOS PARA A INDÚSTRIA DE ALIMENTOS
}

\author{
Sabrina Di Salvo Mastrantonio ${ }^{1}$ \\ José Carlos de Toledo ${ }^{2}$
}

\begin{abstract}
Resumo: $\mathrm{O}$ artigo tem por objetivo analisar as práticas da gestão da qualidade em fabricantes de equipamentos para a indústria de alimentos, no estado de Sáo Paulo. Foi conduzida uma pesquisa de levantamento em uma amostra de 35 empresas. Para análise dos dados, aplicou-se estatística descritiva, análise de correlação e de cluster. A análise de cluster identificou 3 grupos de empresas, diferenciados pelo grau de formalização de procedimentos, existência de um Sistema de Gestão da Qualidade (SGQ) e porte das empresas. As empresas da amostra demonstraram ter consciência das exigências por qualidade e segurança dos equipamentos fornecidos, no entanto, nem todas e nem todos os clientes, associam, ainda, a obtenção de características de qualidade desejadas para o equipamento à estruturação de um Sistema de Gestão da Qualidade. De modo geral, as empresas de maior porte, as multinacionais e as que também fornecem equipamentos para outros setores industriais, mais exigentes em qualidade, tendem a ter um SGQ mais estruturado.
\end{abstract}

Palavras-chave: Gestão da Qualidade. Equipamentos para indústria de alimentos. Indústria de bens de capital para alimentos. Survey.

\begin{abstract}
This paper aims to analyze the quality management practices in equipment manufacturers for the food industry, located in the state of São Paulo. A survey was conducted in a sample of 35 companies. For the data analysis, the following techniques were utilized: descriptive statistics, correlation and cluster analysis, which created 3 groups, differentiated by the degree of procedure formalization, existence of a Quality Management System (QMS) and size of the companies. These companies are aware of the quality and security exigencies of the products offered, nevertheless, not all of them and, seemingly, not all of the clients associate, still, the obtainment of quality characteristics desired to the equipment with the structure of a Quality Management System. As a whole, the large companies, the multinationals and the ones which supply equipment to other industrial sectors, more demanding in quality, tend to have a more structured and formalized QSM.
\end{abstract}

Key Words: Quality management. Equipment for the food industry. Capital goods industry for food. Survey.

1 sabrinadsm@dep.ufscar.br

2 Universidade Federal de São Carlos - UFSCar, Centro de Ciências Exatas e de Tecnologia, Departamento de Engenharia da Produção, Grupo de Estudo e Pesquisa em Qualidade - GEPEQ 
INTRODUÇÃO

O contexto mundial de um maior dinamismo competitivo tem exigido do Estado brasileiro, dos segmentos produtivos e dos agentes do sistema nacional de inovação, um esforço permanente e efetivo para a consolidação de um ambiente favorável ao desenvolvimento da qualidade, à redução de custos e à inovação tecnológica dos produtos e serviços (Ministério do Desenvolvimento, Indústria e Comércio exterior [MDIC], 2007).

A intensificação das mudanças no mercado brasileiro não é apenas condicionada pelo mercado externo, mas também para atendimento às demandas de consumidores internos e às crescentes restriçôes da legislação aplicada a cada segmento de produtos. $\mathrm{O}$ maior nível de exigências dos clientes e de órgáos regulamentadores da qualidade, saúde e meio ambiente também impóem novos e dinâmicos requisitos à qualidade de bens e serviços. Para alcançar melhores níveis de eficiência, as empresas são motivadas a desenvolver atividades de mudanças constantes nos produtos e nos processos produtivos, visando à melhoria da qualidade, nos mais diversos segmentos industriais.

Segundo Avellar (2008), o setor de bens de capital permeia todos os demais por ser responsável pelo fornecimento de máquinas e equipamentos, o que evidencia sua relevância na determinação da competitividade do setor industrial do país e foi um dos setores incluídos no Programa para Fortalecer a Competitividade da política industrial do governo brasileiro, lançado em maio de 2008.

Para Vermulm e Erber (2002) toda empresa de bens de capital, para ser competitiva, necessita ter, além de instalações, máquinas e mão de obra adequadas, competências específicas em engenharia de projeto e de produto, em comercialização e em serviços de assistência técnica pós-venda. No entanto, a heterogeneidade de produtos e processos existente na indústria de bens de capital implica em diferentes açóes e rotinas para que cada um dos segmentos industriais seja capaz de manter a competitividade das empresas em seus mercados. Em um estudo sobre o setor de bens de capital seriados no Brasil, Vermulm (2003) observou que, dentre os segmentos analisados, o mercado interno para máquinas e equipamentos para a indústria de alimentos era um dos maiores, porém pouco estudado e conhecido, apresentando baixos coeficientes de importação e exportação. Constatou, também, que o segmento se destacava por ter um mercado amplo, fornecendo equipamentos para clientes bem heterogêneos quanto a tamanho da empresa, sofisticação tecnológica, origem do capital e segmentos de atuação.

$O$ estado que mais se destaca na fabricação de máquinas e equipamentos para a indústria de alimentos é São Paulo, que abrange entre 60 e $70 \%$ das empresas do setor. Outros estados com representação expressiva neste segmento, logo após o estado de São Paulo, são: Santa Catarina e Rio Grande do Sul. Estes dois estados, por exemplo, concentram grande número de empresas produtoras de bebidas, principalmente vinhos, e acabam atraindo a instalação de empresas de equipamentos para atender a essas indústrias (Associação Brasileira da Indústria de Máquinas e Equipamentos [ABIMAQ], 2007).

Dadas a importância do setor de equipamentos para o processamento de alimentos; a concorrência imposta por fornecedores internacionais; a importância da qualidade desses equipamentos para a sua competitividade, e a participação do estado de São Paulo neste segmento industrial, este trabalho procura responder às seguintes questóes de pesquisa: $\mathrm{O}$ segmento de equipamentos para a indústria de alimentos do estado de São Paulo tem se ajustado às exigências do mercado quanto à qualidade dos produtos e à gestão da qualidade? Com quais práticas? Quais as principais dificuldades enfrentadas na gestão da qualidade neste segmento industrial?

$\mathrm{O}$ artigo tem como objetivo identificar e analisar as práticas da gestáo da qualidade e as principais dificuldades desta gestáo em uma amostra de fabricantes de equipamentos para a indústria de alimentos, localizados no estado de Sáo Paulo. Para atingir este objetivo foi realizada uma pesquisa survey, levantando-se dados em uma amostra, estratificada, de 35 empresas.

\section{GESTÃO DA QUALIDADE}

Nas últimas décadas, devido à saturação dos produtos no mercado, maior competição entre as empresas e globalização econômica e do mercado, o enfoque da qualidade foi alterado: passou a ser exigida pelos clientes e por organismos regulatórios, ao invés de considerar apenas a visão daque- 
les que os produzem, provocando mudanças no conceito da qualidade e na sua gestão (Garvin, 1992; Eckes, 2001). Segundo Battikha (2003), atualmente, as expectativas ou necessidades dos clientes são a base para a definição e variação da qualidade do produto ou serviço. Quanto maiores os padróes de níveis de exigência, os quais tendem a ser incrementados com o avanço da tecnologia e inovação, maiores os graus de qualidade dos produtos e serviços oferecidos, visando a satisfaçáo plena dos clientes.

Principalmente a partir da década de 1970, a qualidade passou a ser vista como uma função de gerenciamento e a abordagem de gestáo para a qualidade aparece como sistêmica e holística, ao invés de apenas corretiva (Garvin, 1992). Crosby (1994) define gestão da qualidade como um meio sistemático de garantir que as atividades da organização aconteçam segundo o planejado, por meio da prevenção de problemas e da criação de atitudes e controles na realização das atividades.

Uma maneira de gerenciar a qualidade nas empresas é utilizar um Sistema de Gestão da Qualidade (SGQ). De acordo com Feigenbaum (1994), um SGQ consiste em uma série de atividades mutuamente relacionadas: pessoas, máquinas, material, métodos e informaçôes, com a finalidade de garantir a qualidade do produto, ao menor custo possível. Se propriamente implementado, um Sistema formal de Gestão da Qualidade é um meio eficaz para se alcançar a qualidade dos produtos ou serviços oferecidos (Battikha, 2003).

Ferreira (2005) apresenta alguns fatores que levaram os Sistemas de Gestão da Qualidade a assumirem um importante papel no contexto internacional:

- - fenômeno da globalização, facilitando o comércio internacional;

- - fortalecimento da Organização Mundial do Comércio (OMC), dificultando a utilização de barreiras tarifárias no comércio internacional;

- - surgimento do conceito do fornecedor de classe mundial, no qual um fornecedor passa a fornecer para seu cliente em todos os países onde ele tem subsidiárias;

- - necessidade de coerência e padronizaçáo na gestáo de múltiplas filiais de uma mesma empresa, distribuídas no mundo;

- - conceito de parceria de longo prazo entre cliente e fornecedor, demandando uma confiança na manutenção dos padróes de qualidade do fornecimento, em termos de qualidade do produto, prazo de entrega, quantidade e preço estável;

- - aumento da concorrência entre fornecedores potenciais, tornando mais difíceis e arriscadas as decisóes de compra com base apenas no preço.

A implantação de um Sistema de Gestão da Qualidade deve envolver todos os processos e agentes da cadeia de valores da organização. $\mathrm{O}$ princípio que o rege é a abordagem por processos, para controle dos processos, identificação e tratamento dos desvios dos procedimentos estabelecidos, além da adoção da filosofia da melhoria contínua, em busca da excelência de atendimento ao cliente e atingir as estratégias da organização (Belga, 2007). Lagrosen (2007) aponta que muitas das melhorias na qualidade de produto e de processo acontecem nas interaçóes entre fornecedores e clientes.

Os documentos usualmente requeridos na Gestão da Qualidade incluem: manual da qualidade; instruções de trabalho, especificações, planos de inspeçóes e testes; relatórios de não conformidades; etc. Estes documentos podem variar de acordo com o padrão do sistema da qualidade adotado (Battikha, 2003).

Planejar e alcançar um maior nível de qualidade é fundamental para que as operaçóes das empresas sejam bem sucedidas. Para tal, é necessário entender e gerenciar várias dinâmicas da organização, a fim de estabelecer objetivos e aplicar os recursos com maior eficiência e eficácia, o que irá depender das boas práticas de gerenciamento que são adotadas.

\section{A INDÚSTRIA DE EQUIPAMENTOS PARA ALIMENTOS}

O setor de bens de capital brasileiro pode ser caracterizado como heterogêneo, concentrado em empresas de grande porte, a maioria multinacionais, mas também com forte presença de pequenas e médias empresas nacionais (Avellar, 2008).

Segundo Valença (2001), o Brasil apresenta diversas vantagens para a consolidação de uma forte indústria de bens de capital: disponibilidade de oferta interna de aço; mercado interno diversificado e demandante de equipamentos e legislação trabalhista razoavelmente flexível. Esses fato- 
res, no entanto, são frequentemente mascarados por uma variável negativa de forte influência: $o$ câmbio. Alem e Pessoa (2005) apontam, também como vantagem competitiva, o baixo custo da máo de obra no país.

No primeiro bimestre de 2008, enquanto o aumento da produçấo foi de 9,2\% no Brasil, em São Paulo, chegou a 11,5\%. Dentre os setores responsáveis por $60 \%$ deste crescimento, destacava-se o setor de máquinas e equipamentos (Instituto de Estudos para o Desenvolvimento Industrial [IEDI], 2008).

Avellar (2008) ressalta que existe uma forte correlaçáo entre as empresas de bens de capital e as características de seus compradores e fornecedores. Desta forma, características distintas são encontradas dentro de cada segmento da indústria de bens de capital, em função das dinâmicas específicas do mercado e da tecnologia, como é o caso do segmento de equipamentos para a indústria de alimentos, que tem sua dinâmica de inovação puxada pela indústria de alimentos.

O mercado mundial de equipamentos para a indústria alimentícia é altamente competitivo e a tecnologia incorporada desempenha um papel determinante. O país líder do segmento é os EUA, responsável por cerca de $25 \%$ da produção mundial, seguido da Uniáo Europeia e Japão. O contínuo crescimento deste segmento pode ser observado tanto nos países mais estruturados da Europa, da América do Norte e Japão, como em importantes países produtores e distribuidores de alimentos como Austrália, Brasil e Argentina. Com o crescimento da populaçáo mundial e o progresso da industrialização, a indústria de alimentos continua se desenvolvendo com a finalidade de aumentar a produção de alimentos e reduzir o seu desperdício, e esta estratégia está fortemente vinculada ao desenvolvimento tecnológico das máquinas e equipamentos para este setor (Avellar, 2008).

$\mathrm{Na}$ cadeia de produçáo de alimentos, o papel dos fornecedores de equipamentos merece destaque, como observado por Domingues e Furtado (2003) em trabalho que analisou a inovação tecnológica na indústria de alimentos. Segundo os autores, a indústria de alimentos é singular pela heterogeneidade de seus segmentos e induz atividades de pesquisa e desenvolvimento ao longo de sua cadeia produtiva, onde o fornecedor de bens de capital exerce um importante papel. As ativi- dades de cooperação mantidas na cadeia de produção refletem em importantes resultados para o processo de inovação na própria indústria de alimentos, através do aprendizado gerado nestas interaçóes da cadeia. Além disso, como apontado por Borrás e Toledo (2007), a crescente preocupação com a segurança e a qualidade dos alimentos, como um dos principais fatores competitivos das cadeias de produção de alimentos, exige que todas as empresas envolvidas na cadeia produtiva busquem mecanismos para melhoria da gestão da qualidade.

Ghobril e Moori (2009), em um trabalho que analisou o alinhamento estratégico entre a indústria de bens de capital e a de alimentos, no Brasil, constataram que a indústria de alimentos, dependendo do seu modelo de produçáo, exige de seus fornecedores de máquinas características diferenciadas, como histórico do fornecedor, suporte pós-venda, facilidade de manutenção, robustez do produto e confiabilidade. As empresas pesquisadas pelos autores foram unânimes em declarar que valorizam em seus fornecedores a qualidade do equipamento, seja de projeto, de design ou de desempenho técnico.

A partir de um levantamento feito em diversas fontes de dados, descrito mais detalhadamente no tópico "método de pesquisa" deste artigo, foram identificadas 245 empresas industriais, desse segmento, no Estado de São Paulo. A maioria delas são empresas nacionais de pequeno porte, nem todas fabricam equipamentos exclusivamente para a indústria de alimentos e a maioria está situada na região da Grande São Paulo.

\section{MÉTODO DE PESQUISA}

O método de pesquisa adotado é a pesquisa de levantamento (survey) seguida da análise estatística dos dados.

De acordo com Forza (2002), o objetivo ao se realizar um survey está em contribuir para elevar o conhecimento em uma área particular de interesse. O survey realizado configura-se como descritivo, o qual se propóe a descrever uma realidade (nesta pesquisa: práticas de Gestão da Qualidade adotadas) em uma amostra de uma determinada população, neste caso, o segmento industrial de bens de capital para a indústria de alimentos, do estado de São Paulo.

Como técnica de pesquisa, foi adotado um 
questionário estruturado, aplicado pessoalmente, por meio de entrevista conduzida com um responsável pelo Departamento da Qualidade (normalmente, o gerente da área) ou com o responsável por esta função na empresa, identificado através de um prévio contato telefônico.

A primeira versão do questionário foi testada em 6 empresas, sendo três de pequeno, duas de médio e uma de grande porte, o que permitiu realizar ajustes e complementaçáo do seu conteúdo. Após a realização deste teste, o questionário foi aplicado em uma amostra representativa de empresas do segmento objeto de estudo. O questionário, em seu formato final era composto por 38 questóes, tendo como possíveis respostas, alternativas graduadas em uma escala de intensidade crescente de 1 a 5. O tempo de aplicação do questionário, em cada empresa, foi de cerca de 2 horas. Os dados foram coletados em um período de 3 meses, o que configura um corte transversal, de acordo com Sampieri et al. (1997).

\section{DEFINIÇÃO DA POPULAÇÃO E DA AMOSTRA}

A população de estudo é o conjunto de empresas que fabricam algum tipo de equipamento para a indústria de alimentos, com unidades de produção no estado de Sáo Paulo. A população de empresas foi levantada com auxílio de um cadastro existente junto à ABIMAQ (2007), da lista das empresas que participaram da FISPAL Tecnologia em 2007 (feira internacional que reúne fabricantes de equipamentos e de embalagens para a indústria de alimentos) e do Anuário das Indústrias do Estado de São Paulo de 2007. Identificou-se um total de 245 empresas, considerando-se as de pequeno, médio e grande porte. Em virtude da extensão da população e de restrições de tempo para condução de um levantamento de dados pessoalmente, foi determinada uma amostra probabilística estratificada para representar a população de estudo.

Segundo Rea e Parker (2002), a finalidade da amostragem é poder fazer generalizaçôes sobre uma população com base em um subconjunto, cientificamente selecionado, dessa população. Pinsonneault e Kraemer (1993) apontam que o elemento mais crítico do procedimento de amostragem é a escolha da fração que constitua uma parcela representativa da população em estudo.
Existem dois tipos de amostra: não probabilística e probabilística. A amostragem probabilística baseia-se na escolha aleatória dos pesquisados, por meio de um sorteio, o que faz com que cada membro da populaçáo tenha a mesma probabilidade de ser escolhido. Além disso, permite a utilização de tratamento estatístico (Lakatos \& Marconi, 1995; Montgomery \& Runger, 2009).

Freitas et al. (2000) subdividem a amostra probabilística em estratificada e não estratificada. A amostra probabilística estratificada consiste em subdividir a população em grupos homogêneos, sendo que cada subgrupo dá origem a uma amostra. Este tipo de procedimento amostral assegura que todos os tipos possíveis estejam presentes na amostra.

Para obter uma amostra probabilística estratificada, a população desta pesquisa foi separada em estratos, com base nos seguintes critérios:

- - porte das empresas (determinado a partir do número de funcionários);

- - localização geográfica em regióes do estado de Sáo Paulo;

- - fabricantes com orientação específica para a indústria de alimentos ou para este e outros setores.

Assim, após a estratificação da população (em 10 estratos, levando-se em conta os critérios apresentados, combinados dois a dois ou três a três), foram sorteadas amostras aleatórias de cada estrato, por meio de uma tabela de números aleatórios, consultados em Hair Jr. et al. (2005). De cada estrato foram extraídas empresas capazes de representarem as demais empresas (o número de empresas sorteadas em cada estrato foi proporcional ao tamanho do estrato). O tamanho total da amostra foi delimitado em, no mínimo, 30 e, no máximo, 40 empresas, levando-se em conta a limitação de tempo e de recursos para a condução de um survey presencial e a possibilidade de se fazer análises estatísticas e inferências a partir da amostra (estratificada e representativa da população). Após a estratificação e os contatos telefônicos iniciais, foi obtida uma amostra de 35 empresas. Todas elas foram visitadas e os 35 questionários foram aproveitados.

Esses procedimentos para definição da amostra foram necessários para garantir a máxima representatividade da amostra. 


\section{ELABORAÇÃO DO QUESTIONÁRIO E FORMA DE ANÁLISE DOS RESULTADOS}

Os constructos e as variáveis da pesquisa de campo foram determinados a partir da revisão bibliográfica, considerando o escopo tradicional de atuação da gestáo da qualidade, a partir dos trabalhos de Juran e Gryna (1991), Feigenbaum (1994), Toledo e Carpinetti (2000) e Carvalho e Paladini (2006). Para suporte à elaboraçáo do questionário, foi construído um diagrama em árvore delimitando os constructos e as variáveis. Este diagrama (Figura 1) foi o modelo conceitual que deu origem às variáveis e perguntas do questionário e foi baseado no modelo elaborado por Scalco (1999).

Para a elaboração do diagrama, parte-se de um conceito amplo de Gestão da Qualidade. Esta é composta por constructos, que são apresentados em negrito. Cada constructo se desdobra em variáveis e, consequentemente, nas questóes do instrumento de pesquisa. O questionário também levantou informaçôes sobre problemas enfrentados pelas empresas e preocupaçóes futuras, ou seja tendências, em relação à gestão da qualidade.

Para validação do questionário, foi utilizada análise de consistência interna pelo cálculo do alfa de Cronbach, que mede a confiabilidade do instrumento de pesquisa, assumindo valores entre 0 e 1 . Valores acima de 0,70 indicam a boa capacidade do questionário em captar as informações desejadas, sendo aceitos valores até 0,60 em pesquisas exploratórias. O valor do alfa de Cronbach obtido, considerando o conjunto das questóes do questionário, foi 0,9563 .

Pode-se admitir, com base neste valor, que o questionário estava adequado para caracterização das práticas adotadas para gestão da qualidade no segmento de equipamentos para a indústria de alimentos. Os dados obtidos na pesquisa de campo foram compilados e tratados por meio de técnicas de análise de correlação e análise de cluster, utilizando-se o software Statistica 8.0.

Como o tamanho da amostra obtida é relativamente pequeno, considerando o tamanho da populaçáo (apesar de ter sido utilizada uma amostragem com estratificação da populaçáo, visando garantir a sua representatividade), não foi possível realizar um teste recomendado para se identificar os constructos a serem utilizados na análise de cluster: a análise fatorial. Além disso, outro empecilho para aplicaçáo desta análise é o fato de nem todas as questóes terem sido respondidas por todos os respondentes, uma vez que algumas delas eram respondidas apenas pelas empresas com um SGQ implantado, o que reduziria, ainda mais, o tamanho da amostra para aplicação do teste. A análise fatorial também poderia ser empregada para confirmar (ou não) a distribuição das questôes em cada um dos temas (constructos).

\section{WORKSHOP PARA DISCUSSÃO DOS RESULTADOS}

Ao final da pesquisa de campo e compilação dos dados, com a elaboração das conclusôes prévias, foi realizado um workshop com objetivo de validar os resultados obtidos, dar retorno às empresas participantes da pesquisa, bem como discutir possíveis açôes para melhoria da gestão da qualidade nessas empresas.

O workshop foi realizado na sede da ABIMAQ, na cidade Sáo Paulo, como pauta de reunião da CSMIAFRI (Câmara Setorial de Máquinas para a Indústria Alimentícia, Farmacêutica e de Refrigeração Industrial). Participaram do evento 18 pessoas, representando 13 empresas do setor. Desta forma, foi possível, além de dar retorno às empresas que participaram da pesquisa de campo, estender a divulgação dos resultados e a discussão do tema também às empresas náo participantes, mas que, por fazerem parte do segmento estudado, são diretamente interessadas nos resultados. $\mathrm{O}$ workshop promoveu a discussão sobre a importância da Gestáo da Qualidade nas empresas, a reflexão sobre os problemas enfrentados atualmente (com relaçáo à qualidade do produto e à gestáo da qualidade) e a troca de experiências sobre açôes já adotadas ou que poderiam ser tomadas pelas empresas, para contornar estes problemas.

\section{RESULTADOS}

\section{PERFIL DA AMOSTRA}

Pode-se caracterizar a amostra de empresas como sendo:

- - concentrada na regiáo da Grande São Paulo (Mesorregião Metropolitana Paulista). Segundo profissionais do setor, a maior parte das empresas da população, e da amos- 


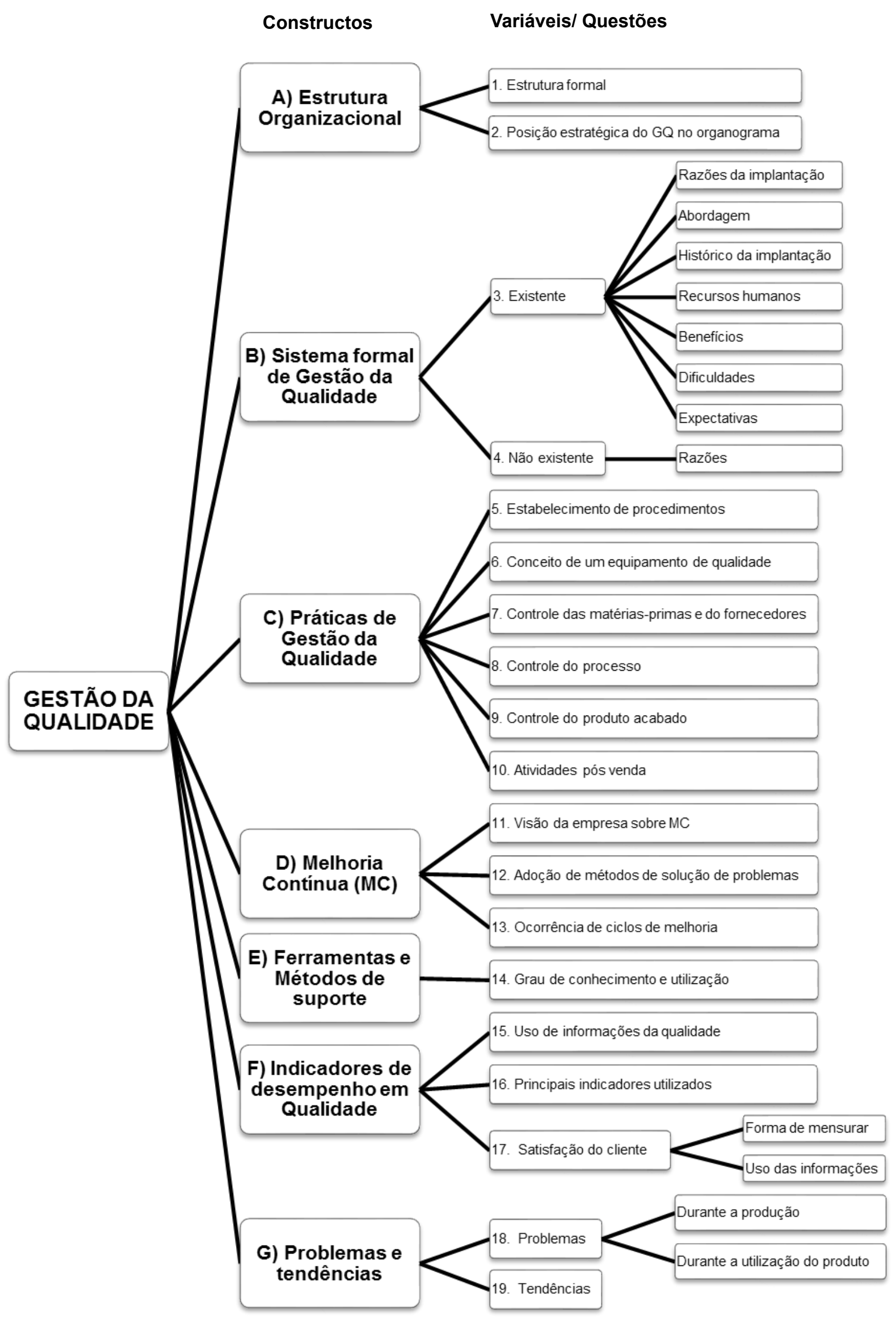

FIGURA 1. Modelo conceitual das variáveis de estudo Fonte: Elaborado pelos autores 
tra, está concentrada nesta região devido à maior disponibilidade de mão de obra e matéria-prima e facilidade de transporte da matéria-prima e de produto acabado;

- predominantemente de administração profissional (45,7\% das empresas), apesar de uma parcela das empresas ainda ser administrada exclusivamente por membros da família proprietária $(37,1 \%)$;

- - predominantemente de capital nacional $(60 \%)$;

- - composta, em sua maioria, por empresas de pequeno porte $(54,3 \%$ das empresas da amostra);

- - voltada para o mercado nacional, apesar de $80 \%$ das empresas exportarem, em pequeno volume, seus produtos. $\mathrm{O}$ faturamento com exportação não chega a $10 \%$ em $55,5 \%$ das empresas entrevistadas;

- - diversificada em seu ramo de atuação, fornecendo equipamentos para os mais variados setores industriais, devido à aplicabilidade de equipamentos em aço inox em outros setores industriais, tais como farmacêutico e petroquímico.

\section{ANÁLISE DESCRITIVA}

Em relação às práticas de Gestão da Qualidade adotadas (implantação de Sistema de Gestão da Qualidade, uso de Métodos e Ferramentas, adoção de Indicadores de Desempenho, principais Problemas e Tendências), a compilaçáo dos dados, por meio de técnicas de estatística descritiva, permitiu algumas constataçóes.

Observou-se que nem todas as empresas possuem um departamento ou pessoas responsáveis pela gerência da qualidade. Em $80 \%$ das empresas, existe uma área designada para tal, mas em $28,6 \%$, esta função é designada a um ou mais funcionários subordinados a outro Departamento, ou seja, existe a área funcional da Qualidade, mas com status inferior ao de outras áreas funcionais. Além disso, em pouco mais de 50\% das empresas, o número de profissionais atuantes diretamente na área da Qualidade é pouco expressivo: de $1 \mathrm{a}$ 3 funcionários. Ambas as constataçóes podem ser explicadas pelo quadro enxuto de funcionários apresentado pela maioria dessas empresas.

A documentação dos procedimentos e das rotinas de trabalho, das fichas de operaçáo e pla- nos de controle da qualidade, mesmo que parcialmente e não necessariamente controlados, é adotada pela maioria das empresas entrevistadas $(91,4 \%)$.

Conceitualmente, as empresas têm uma visão adequada de que um equipamento de qualidade é aquele que atende às expectativas plenas do cliente, mas a maioria, na prática, tem uma atuaçáo gerencial voltada apenas para o Controle da Qualidade do processo produtivo e náo para a Gestão da Qualidade da empresa como um todo.

De modo geral, as empresas têm uma preocupação com a qualidade das matérias-primas, exigindo certificados de qualidade assegurada de algumas delas (as mais críticas) e inspecionam a conformidade das demais durante o recebimento da matéria-prima.

As empresas estão cientes da importância do controle do processo, investindo na realização de testes não destrutivos, para identificação, por exemplo, de falhas de solda, considerada uma atividade crítica para a qualidade do equipamento.

A maioria possui uma relação estreita com os clientes, instalando e testando os equipamentos na planta do cliente, fazendo a chamada "entrega técnica”, e dando treinamento aos futuros usuários, além de prestar assistência técnica, mesmo após o término do período de garantia.

A maioria $(74,3 \%)$, mesmo sem ter um SGQ ISO 9001 implantando e/ou certificado, afirma ter seus procedimentos documentados. Em 31,4\% das empresas existe um SGQ ISO 9001 certificado. Para as que ainda não tem um SGQ implantado e/ou certificado, o principal motivo alegado é a náo exigência pelos clientes, conforme apresentado na Figura 2.

O principal fator que levou as empresas a adotarem um SGQ foi a iniciativa própria para melhorar a qualidade e a produtividade. A exigência dos clientes foi apontada entre os fatores de menor relevância, o que confirma a observação anterior de que as empresas alimentícias não exigem que seus fornecedores tenham um SGQ.

A maioria das empresas que já adotou um SGQ formalizado tinha tomado essa iniciativa há pelo menos 4 anos antes da realização desta pesquisa de campo, e concluíram a implantação em menos de 1 ano. $\mathrm{O}$ tempo relativamente rápido para concluir a implantação pode estar relacionado ao fato da maioria das empresas ter contratado um serviço de consultoria. 
As empresas que adotaram um SGQ formal percebem como principal benefício, além da sistematização da gestão da qualidade na empresa e dos procedimentos de trabalho, o aumento do compromisso dos dirigentes da empresa com a qualidade. E como maiores dificuldades apontaram enfrentar barreiras culturais tais como: resistências internas e falhas em seguir as práticas e procedimentos estabelecidos, conforme consta nas Figuras 3 e 4.
Como principal expectativa em relação ao SGQ, futuramente as empresas visam à diminuição dos custos do produto, seguindo a lógica de que, trabalhando com qualidade, é possível diminuir refugos e retrabalhos e, consequentemente, diminuir os custos de produçáo.

As questôes abordadas sobre melhoria contínua captaram pouca diferença entre as empresas. Uma possível explicação é a difusão, comum no meio de muitas empresas de pequeno e médio

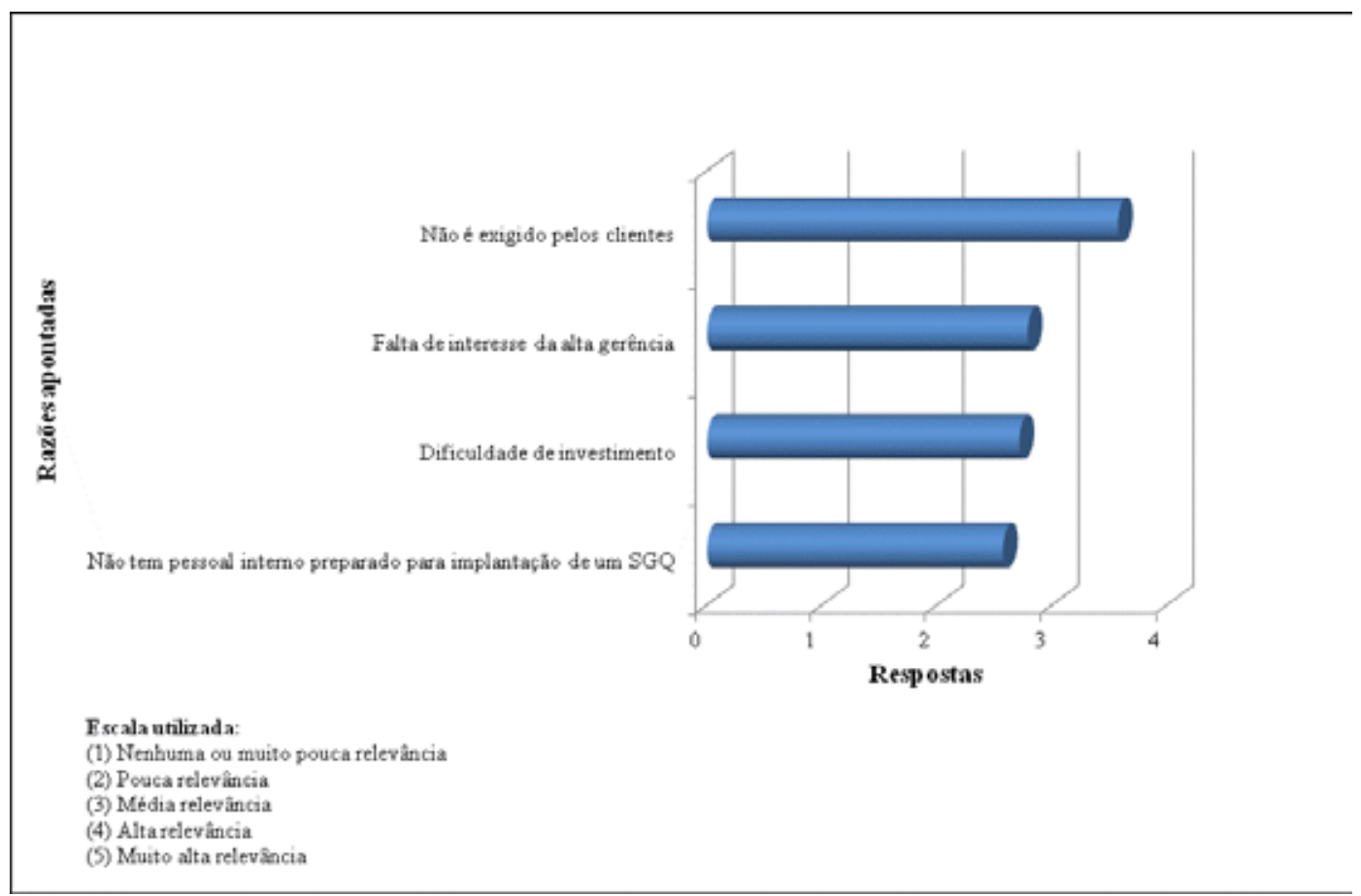

FIGURA 2. Razóes apontadas pelas empresas que ainda não implantaram um SGQ

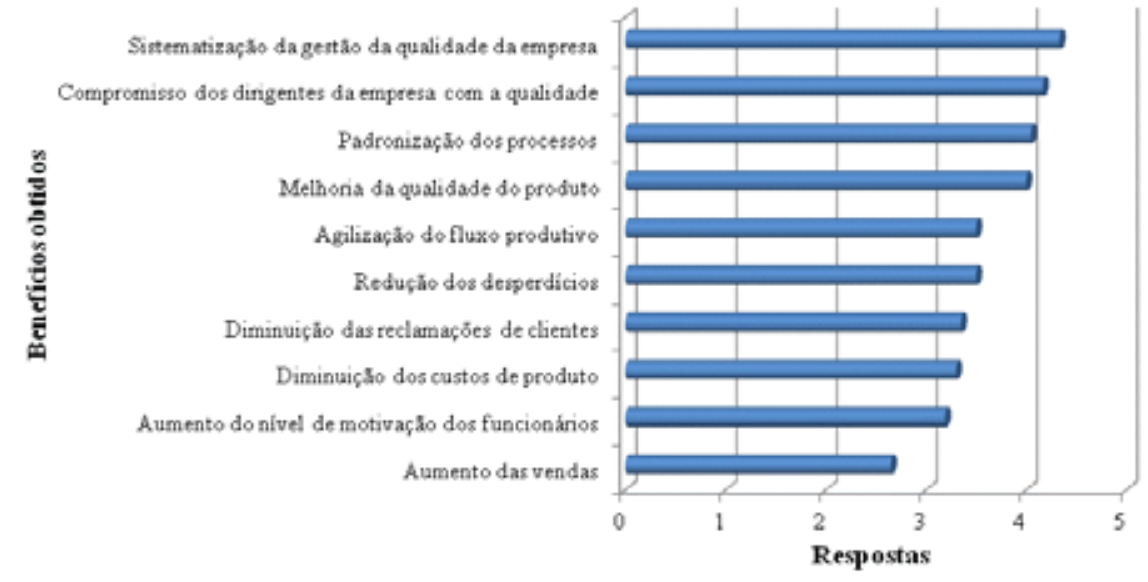

Escala utilizada:

(1) Nenhuma ou muito modesto

(2) Modesto

(3) Modio

(4) Subutacial

(5) Duito substancial

FIGURA 3. Benefícios obtidos com a implantação de um SGQ 
porte, do conceito de melhoria contínua como uma forma simples e de escopo limitado de aplicação de métodos de solução de problemas pontuais e de forma reativa. De modo geral, as empresas conhecem os métodos e ferramentas de apoio à GQ, mas poucas os utilizam regularmente. valar ou de razão e não apresentam uma distribuição normal. Os coeficientes de correlação assumem valores de $-1 \mathrm{a}+1$ e a correlação pode ser interpretada conforme a escala a seguir: $0,00-0,19$ : bem fraca; $0,20-0,39$ : fraca; $0,40-0,69$ : moderada; $0,70-0,89$ : forte; $0,90-1,00$ : muito forte.

\section{Dificuldades enfrentadas na implantação e manutenção do Sistema de Gestão da Qualidade}

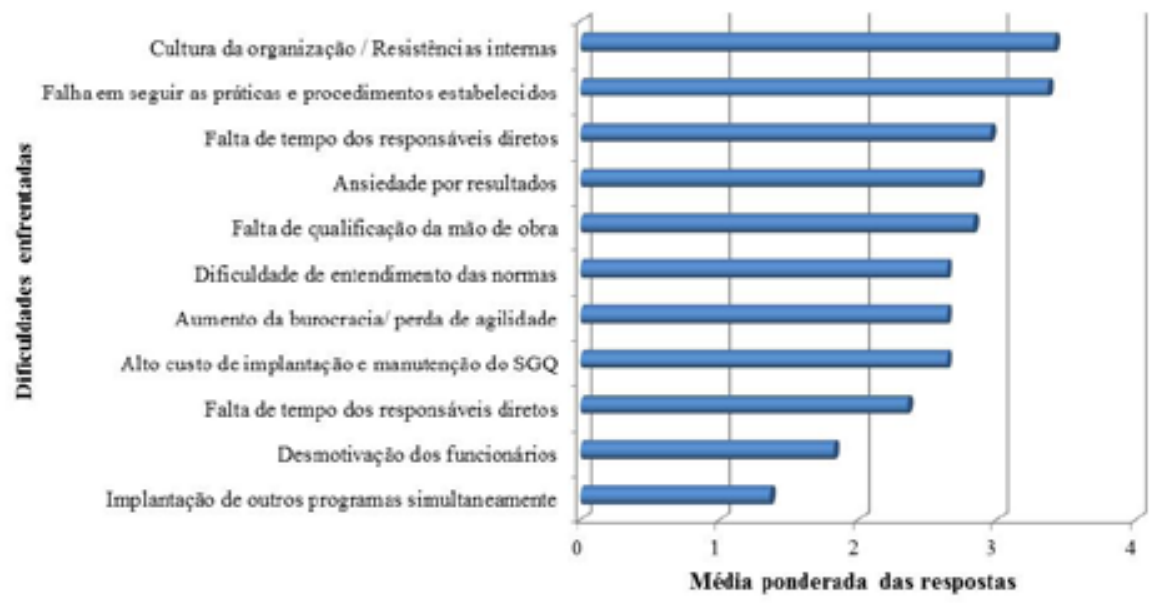

Escala utilizada:

(1) Nenhuma ou muito baixa

(2) Baixa

(3) Média

(4) Alta

(5) Muito alta

FIGURA 4. Dificuldades enfrentadas na implantação de um SGQ

Uma das mudanças pretendidas por muitas empresas $(94,3 \%)$ é a adoção de métodos e ferramentas. Os principais problemas, percebidos em relaçáo à qualidade, apontados com maior pontuação média pela amostra de empresas, são: curto prazo para fabricação dos equipamentos encomendados, sobrecarregando os funcionários e o setor de produção e; mão de obra usuária dos equipamentos, nos processos dos clientes, não devidamente capacitada e treinada.

\section{ANÁLISE DE CORRELAÇÃO}

Coeficientes de associação ou correlação são medidas que descrevem a associação, ou dependência, entre duas variáveis (Morettin \& Bussab, 2004). Malhotra (2001) sugere a utilização do coeficiente rho de Spearman (r) para variáveis não métricas (ordinais e numéricas), uma vez que estas variáveis não dispóem de propriedades de escalonamento inter-
Para este trabalho, foram encontradas poucas correlaçôes significativas entre as variáveis pesquisadas sobre a gestão da qualidade nas empresas. A Tabela 1 apresenta todas as correlaçóes calculadas e as válidas para os níveis de significância de $99 \%(\mathrm{p}<0,01)$ e de $95 \%(\mathrm{p}<0,05)$ são destacadas em negrito. A partir das correlaçóes obtidas, pode-se inferir que:

a. o tipo de administração está correlacionado com a não exigência de um SGQ pelos clientes, o que significa que as empresas de administração familiar são menos cobradas pelos seus clientes ou náo percebem essa cobrança. Outros fatores, como a tradiçáo da empresa no mercado, podem ser mais relevantes na decisão de escolha de uma empresa fornecedora de equipamentos do que a existência de um SGQ formalizado. A maioria das empresas de administração familiar foi instalada entre 1935 e 1985 (84,6\% das empresas), tempo que pode ter sido suficiente para as empresas se consolidarem no mercado e conquistarem e man- 
terem seus clientes, independentemente de terem um SGQ formalizado. Do total de empresas que são de administração familiar, $61,5 \%$ não tem um SGQ implementado e atribuem, como fator mais relevante, a não exigência pelos clientes;

b. o tipo de administração também está relacionado com a visão de melhoria contínua e com a forma de conduçáo da soluçáo de problemas: as empresas de administração profissional têm o conceito de melhoria contínua melhor difundido entre os funcionários e resolvem seus problemas de maneira mais estruturada. Esta correlação pode ser explicada pela maior organização de uma empresa de administraçáo profissional, quando comparada à uma de administração familiar, facilitando a adoção de programas de melhoria. Em empresas de administração familiar, os gestores acreditam ter controle de tudo, guardando informaçóes na memória e fazendo pouco uso de registros;

c. o tipo de capital da empresa aparece correlacionado com o grau de relacionamento com o cliente após a venda, o que indica que empresas de capital estrangeiro têm uma política de relacionamento com o cliente mais consolidada do que as nacionais. As empresas multinacionais parecem se preocupar mais com o relacionamento com seus clientes, dando mais importância a um atendimento diferenciado, que procure fortalecer relaçóes de parceira e de longo prazo do que as empresas nacionais. Do total de empresas de capital estrangeiro ou misto, $85,7 \%$ afirmaram ter esta preocupação;

d. empresas que fornecem para diferentes setores industriais (não só para o setor alimentício) têm maior chance de ter uma área responsável pela gerência da qualidade, o que permite concluir que a indústria alimentícia é um cliente menos exigente quanto à Gestáo da Qualidade dos seus fornecedores de equipamentos;

e. as empresas de maior porte tendem, mais do que as pequenas, a ter uma área responsável pela gerência da qualidade e uma maior formalizaçáo de seus procedimentos e atividades para controle dos processos, de produção e de suporte, o que pode ser explicado pela maior disponibilidade de pessoas para realização das atividades de gestão da qualidade e de suporte às operaçóes. O porte da empresa condiciona náo apenas uma maior disponibilidade de pessoas e de estrutura organizacional, como também exige uma maior organização da empresa quanto à documentação de seus procedimentos, para que estes estejam sob controle dos dirigentes. A quantidade de informaçóes processadas e de processos gerenciados é diretamente proporcional ao porte da empresa e a necessidade de organização da documentação para controle dos processos é percebida mais rapidamente pelas empresas de maior porte;

f. o porte também aparece correlacionado com a existência de um SGQ formal e com o tempo decorrido desde a implantaçáo deste sistema, o que sugere que neste segmento as empresas de maior porte têm maior probabilidade de ter um SGQ implantado e há mais tempo do que as empresas menores. Esta constataçáo pode ser reforçada pelo mesmo motivo apontado anteriormente: as empresas maiores percebem a necessidade de organização mais rapidamente do que as de menor porte. Outros motivos que podem estar associados são a maior disponibilidade de recursos humanos e financeiros. Empresas de maior porte têm maior quantidade de funcionários delegados para funçôes específicas e a implantação de um SGQ não é barrada por restriçôes orçamentárias, motivo este alegado por algumas empresas menores;

g. o porte da empresa aparece correlacionado negativamente com os problemas do tipo: falta de mão de obra qualificada e mão de obra usuária náo devidamente treinada, o que indica que as empresas menores têm maiores dificuldades na contratação de mão de obra para atuar nos seus processos e no treinamento da mão de obra do cliente que irá operar os equipamentos fornecidos, possivelmente por terem restriçóes de orçamento e de pessoal;

h. a existência de uma área responsável pela gerência qualidade está relacionada com um maior formalismo dos procedimentos, uma vez que a formalização e documentação dos procedimentos demandam tempo. A disponibilidade de funcionários dedicados integralmente à área da Qualidade agiliza este processo;

i. a existência de um SGQ formal está positivamente correlacionada com: a existência de uma área responsável pela gerência da qualidade, grau de formalização dos procedimentos e conceito de um equipamento de qualidade. Isto pode ser explicado pelo fato da existência de um SGQ demandar da empresa uma melhor estrutura organizacional, como a existência de uma área própria 


\begin{tabular}{|c|c|c|c|c|c|c|c|c|c|c|c|c|c|c|c|}
\hline & & \multirow{2}{*}{ 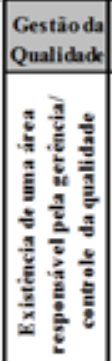 } & \multicolumn{3}{|c|}{$\begin{array}{c}\text { Práticas de Gestào } \\
\text { da Qealidade }\end{array}$} & \multicolumn{3}{|c|}{$\begin{array}{c}\text { Sis tema de } \\
\text { Gestão da Qualidade }\end{array}$} & \multicolumn{3}{|c|}{ Melhoria Continua } & \multicolumn{4}{|c|}{ Problemas } \\
\hline & & & 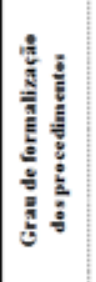 & 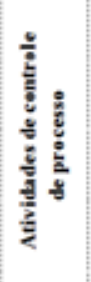 & 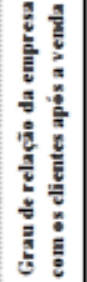 & 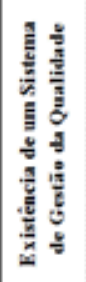 & 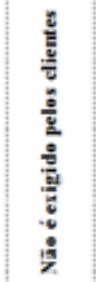 & 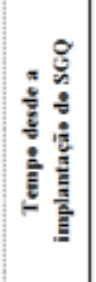 & 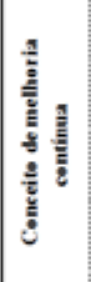 & 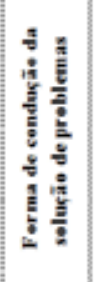 & 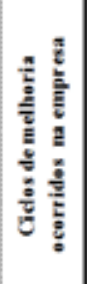 & 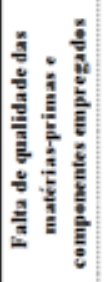 & 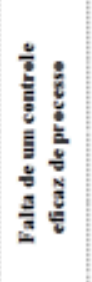 & 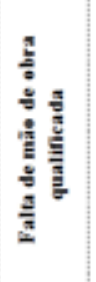 & 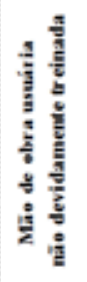 \\
\hline \multirow{4}{*}{$\begin{array}{c}\text { Caracterizaçào } \\
\text { Geral }\end{array}$} & Tipo de adminis tr aç ào & 0,203 & 0,256 & 0,027 & $-0,096$ & 0,321 & $-0,693^{* *}$ & 0,073 & $0,408 *$ & $0,365^{*}$ & 0,081 & $-0,023$ & $-0,297$ & $-0,302$ & $-0,290$ \\
\hline & Capital da empresa & 0,275 & 0,145 & $-0,218$ & $0,443^{* *}$ & 0,121 & 0,384 & 0,161 & 0,013 & 0,171 & 0,045 & 0,180 & 0,220 & 0,039 & $-0,010$ \\
\hline & Porte do empresa & $0,364 *$ & $0,494^{* *}$ & $0,424^{*}$ & 0,045 & $0,505 * *$ & $-0,275$ & $0,483 * *$ & 0,118 & 0,249 & 0,090 & 0,068 & $-0,171$ & $-0,363 *$ & $-0,412^{*}$ \\
\hline & Tipos de elientes & $0,365^{*}$ & 0,315 & 0,064 & 0,031 & 0,222 & 0,039 & 0,203 & 0,049 & 0,105 & $-0,052$ & $-0,111$ & $-0,152$ & 0,035 & $-0,036$ \\
\hline $\begin{array}{l}\text { Gestào da } \\
\text { Qualidade }\end{array}$ & $\begin{array}{l}\text { Existência de uma área } \\
\text { responsível pela geréneia/ } \\
\text { coatrole da qualidade }\end{array}$ & $x$ & $0,378 *$ & 0,084 & 0,273 & $0,463^{* *}$ & 0,129 & 0,348 & 0,022 & 0,048 & $-0,200$ & 0,100 & $-0,008$ & $-0,251$ & $-0,133$ \\
\hline \multirow{2}{*}{$\begin{array}{l}\text { Príticas de } \\
\text { Gestaio da } \\
\text { Qualidade }\end{array}$} & $\begin{array}{l}\text { Grau de formalizaç ào dos } \\
\text { procedimentos }\end{array}$ & $0,378^{*}$ & $\mathrm{x}$ & $0,439 * *$ & 0,175 & $0,765 * *$ & 0,300 & $0,703 * *$ & 0,037 & 0,299 & $0,365^{*}$ & $-0,048$ & $-0,045$ & $-0,124$ & $-0,201$ \\
\hline & $\begin{array}{l}\text { Canceito de miquina/ } \\
\text { equipamento de qualidade }\end{array}$ & 0,184 & 0,289 & 0,248 & 0,248 & $0,365^{*}$ & $-0,123$ & 0,374 & 0,266 & 0,249 & $-0,005$ & $-0,218$ & $-0,240$ & 0,108 & $-0,088$ \\
\hline \multirow{2}{*}{$\begin{array}{l}\text { Melhoria } \\
\text { Continua }\end{array}$} & Conceito de melhoria contiaua & 0,022 & 0,037 & 0,128 & $-0,069$ & 0,175 & $-0,186$ & 0,147 & $\mathrm{x}$ & $0,465^{* *}$ & 0,160 & $-0,486 * *$ & $-0,418^{* *}$ & 0,005 & 0,108 \\
\hline & $\begin{array}{l}\text { For ma de coedaçào da solaçio } \\
\text { de problemas }\end{array}$ & 0,048 & 0,299 & 0,075 & $-0,126$ & 0,263 & $-0,170$ & 0,042 & $0,465 * *$ & $\mathrm{x}$ & 0,271 & $-0,322$ & $-0,155$ & $-0,110$ & $-0,294$ \\
\hline
\end{tabular}

Nota: $\mathrm{O} X$ indica a variável foi confrontada com ela mesma.

para a Qualidade e a formalização de procedimentos referentes a todos os processos que ocorrem na empresa. O conceito relativamente mais avançado do que seria um equipamento de qualidade também pode ser influenciado pela existência de um SGQ, uma vez que uma das obrigaçôes é ter definido qual é a missão da empresa e a maioria delas é unânime no entendimento de "satisfazer as necessidades dos clientes";

j. o grau de formalização dos procedimentos aparece correlacionado com o grau de adoção de atividades de controle do processo, com a existência de um SGQ, com o tempo desde a implantação do SGQ e com a ocorrência de ciclos de melhoria na empresa, o que sugere que a existência de procedimentos é uma etapa básica em direção à implantação de um SGQ e de atividades de controle de processo e de melhoria contínua;

k. o conceito adotado e a visão de melhoria contínua aparece correlacionado, negativamente, com os problemas: falta de qualidade de matérias-primas utilizadas e falta de um controle eficaz do processo, o que leva a supor que as empresas menos cientes do conceito de melhoria contínua enfrentam estes problemas mais frequentemente em relação àquelas que procuram, continuamente, a melhoria de suas atividades. A prática da melhoria contínua pode auxiliar na identificação da origem dos problemas da qualidade das matérias primas e no controle do processo, evitando a continuidade dos problemas;

1. a ocorrência de ciclos de melhoria também aparece correlacionada com o grau de formalização dos procedimentos, mostrando que quanto mais estruturada a empresa em relação aos seus procedimentos para a qualidade, mais avançada ela também se encontra em relação à prática de ciclos de melhoria. A prática de melhoria contínua passou a ser obrigatória a partir da versão $2000 \mathrm{da}$ ISO 9001 e, desta forma, as empresas certificadas ou não pela norma, mas que seguem as diretrizes da ISO 9001, praticam melhoria contínua em algum grau.

Outras correlaçóes não apresentadas na Tabela 1, por não serem apontadas como significativas, mas que apresentam valores considerados moderados, confrontam as variáveis escolhidas para a formação do cluster com alguns resultados esperados com a implantação de um SGQ e tem seus valores indicados e comentadas a seguir:

- Correlação entre as variáveis: conceito de máquina/ equipamento de qualidade versus aumento de vendas: $\mathbf{0 , 4 6 3 5}$

Essa correlação indica que a forma como a empresa entende o conceito de um equipamento de qualidade, que em última instância, visa satisfazer as necessidades do cliente, reflete no aumento da lucratividade, com o aumento das vendas.

- Correlaçáo entre as variáveis: grau de implantação de atividades de controle de processo 
versus diminuição dos custos do produto: $\mathbf{0 , 4 0 7 9}$

A preocupação da empresa em estruturar os processos, com atividades de controle, reflete na diminuição dos custos dos produtos, por redução de refugos e retrabalhos.

\section{ANÁLISE DE CLUSTER}

Para a análise de cluster foram escolhidas 8 questôes (Tabela 2), pertencentes aos tópicos "Estrutura Organizacional para a Qualidade" (questão 9a), "Práticas de Gestão da Qualidade" (questôes 11 a16) e "Sistema de Gestáo da Qualidade" (questão 17), que foram respondidas por todas as empresas da amostra, uma vez que uma parte do questionário era direcionada apenas às empresas com SGQ implantando.

Assim, as questóes consideradas como base para a formaçáo dos agrupamentos estavam associadas com o grau de implantação do SGQ. A partir das respostas obtidas para cada uma destas questôes, adotou-se o critério $k$-means, que forma os grupos com base na diferença das médias das respostas. Este mesmo critério foi utilizado no trabalho de Couto Jr e Galdi (2012), os quais o apontam como o método mais utilizado por pesquisadores. Optou-se pela formação de três agrupamentos e os seguintes grupos foram obtidos: I, contendo $40 \%$ das empresas; II, com $20 \%$ e o grupo III com $40 \%$.

$\mathrm{O}$ discernimento dos agrupamentos por meio de cada uma das variáveis pode ser observado pelo p-valor obtido no teste de significância estatística. Quanto menor o p-valor, maior a capacidade de discernimento dos grupos em relação àquela variável. A Tabela 2 apresenta os valores de "p" para cada uma das variáveis. As questóes com maior capacidade para diferenciar os agrupamentos são as que abordam, respectivamente: "grau de formalização dos procedimentos e/ou rotinas de trabalho, fichas de operação e planos de controle voltados para a Gestão da Qualidade”; “atividades de controle de processo" e "grau de implantação de um Sistema de Gestão da Qualidade”.

O gráfico gerado no software Statistica (Figura 5), que apresenta as médias das respostas (no eixo Y, estão os valores da escala de 1 a 5 das respostas) para cada um dos clusters, ilustra o distanciamento dos agrupamentos em relação a cada uma das variáveis consideradas (questóes apresentadas no eixo $\mathrm{X}$ ).

As questôes 11, 14 e 17 são, visualmente, as que mais discernem os grupos entre si, confirmando os valores obtidos com o cálculo do p-valor.

Os 3 grupos formados podem ser caracterizados, resumidamente, por: Grupo I, composto por empresas de médio e grande porte, com SGQ certificado nos moldes da ISO 9001; Grupo II, formado por empresas de pequeno porte, que não possuem procedimentos ou os têm apenas parcialmente documentados e o Grupo III, composto por pequenas e médias empresas que têm seus procedimentos formalizados, algumas em fase de implantação da ISO 9001. Percebe-se, neste caso, a influência do porte da empresa na adoção de práticas de gestão da qualidade.

\section{TABELA 2. p-valor para as variáveis utilizadas na análise de cluster}

\begin{tabular}{|c|c|c|}
\hline Questáo & Enunciado da questáo & p-valor \\
\hline Q9a & Existência de uma área responsável pela gerência/controle da qualidade. & 0,038889 \\
\hline$\underline{Q 11}$ & $\begin{array}{c}\text { Grau de formalização dos procedimentos e/ou rotinas de trabalho, fichas de operação e } \\
\text { planos de controle voltados para a Gestão da Qualidade. }\end{array}$ & $\underline{\mathbf{0 , 0 0 0 0 0 0}}$ \\
\hline Q12 & Conceito de um equipamento de qualidade, na visão da empresa. & 0,045744 \\
\hline Q13 & Controle de qualidade das matérias-primas e componentes. & 0,958593 \\
\hline$\underline{Q 14}$ & Atividades de controle de processo. & $\underline{\mathbf{0 , 0 0 7 1 2 5}}$ \\
\hline Q15 & Inspeçáo final dos equipamentos. & 0,015028 \\
\hline Q16 & Relação da empresa com seus clientes após a venda. & 0,082330 \\
\hline$\underline{Q 17}$ & Grau de implantação de um SGQ. & $\underline{0,000000}$ \\
\hline
\end{tabular}




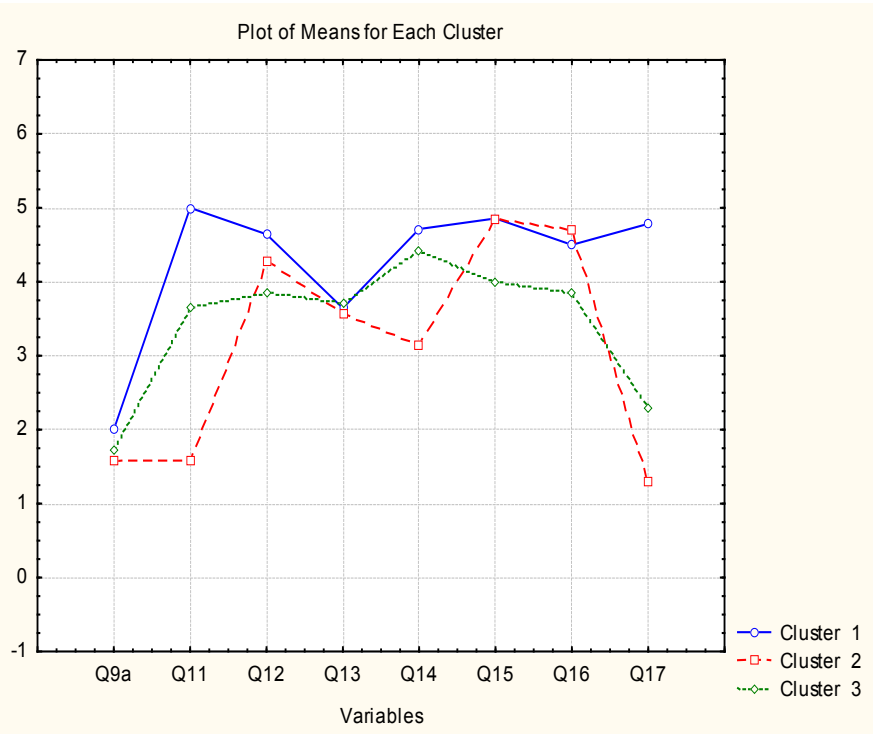

FIGURA 5. Médias das variáveis para cada cluster

Pelas características apresentadas por cada um dos Grupos, é possível supor uma escala gradual e crescente da evolução e maturidade da estruturação da Gestão da Qualidade entre os Grupos, na seguinte sequência: Grupo II, Grupo III e Grupo I.

\section{CONSIDERAÇÓES FINAIS}

O trabalho analisou as práticas da Gestão da Qualidade em empresas fabricantes de bens de capital para a indústria de alimentos e classificou as empresas em grupos com características similares.

Observou-se que, na maioria das empresas estudadas, a adoção de um Sistema de Gestão da Qualidade, e sua subsequente certificação, é um processo voluntário, apoiado pelas próprias motivaçóes, objetivos e políticas da organização e, neste caso, menos influenciado por exigências de clientes, conforme também observou Sampaio et al. (2009) ao conduzir uma pesquisa de campo em empresas industriais do continente europeu, sobre implantação e certificação de SGQ com base na ISO 9001.

No segmento de bens de capital para a indústria de alimentos, percebe-se que as empresas têm a consciência das exigências por qualidade e segurança dos equipamentos, no entanto, nem todas as empresas, e os próprios clientes, associam as características de qualidade do produto à estruturação de um Sistema de Gestão da Qualidade. Apesar da qualidade e segurança do produto ser uma exigência geral no setor, a existência de um SGQ não o é, o que em parte contraria as expectativas iniciais deste trabalho e de algumas publicaçóes na área. No entanto, as empresas que também fornecem para outros setores mais exigentes, como, por exemplo, o petroquímico, ou que visualizam os benefícios na melhoria da qualidade dos produtos e da produtividade que podem ser alcançados com a adoção de um SGQ estruturado, já se anteciparam a possíveis exigências futuras de seus clientes.

As empresas que fornecem equipamentos para a indústria de alimentos são bem diversificadas em seu ramo de atuação, uma vez que equipamentos em aço inox são exigidos por indústrias de outros ramos, tais como farmacêutico e petroquímico. Portanto, estudar o segmento de equipamentos para a indústria de alimentos é, também, estudar algumas especificidades de outros segmentos. O setor petroquímico, por exemplo, é bastante rigoroso para a aquisição de um equipamento, exigindo de seus fornecedores, no mínimo, a certificação do SGQ pela norma ISO 9001, além do uso de normas técnicas sobre o produto.

A indústria de alimentos, em geral, não demanda de seus fornecedores de equipamentos uma certificaçáo ISO 9001. No entanto, algumas empresas do setor já têm exigido esta e outras certificações, tais como a ISO 22000, que é aplicável a toda a cadeia produtiva de alimentos. Essa exigência, como percebido em algumas empresas, acontece e é repassada para toda a cadeia de produção. As empresas alimentícias que fornecem para empresas certificadas são obrigadas a se certificarem e, por sua vez, terem seus fornecedores também certificados.

Todos os grupos de empresas afirmaram a intenção de implantar novas ferramentas e métodos de apoio à Gestáo da Qualidade. Muitas das ferramentas e métodos são conhecidas pelos representantes das empresas entrevistadas, porém são pouco aplicadas. A utilização destas, de forma adequada, poderia ser um importante apoio para a prevenção, deteç̧ão e correção de problemas de qualidade com os equipamentos a tempo, reduzindo os custos da não qualidade.

Os principais problemas percebidos, em relação à gestáo da qualidade, apontados com maior pontuação média pelas empresas são: curto prazo para fabricação, sobrecarregando os funcionários, o que acaba prejudicando a qualidade; máo de obra usuária dos equipamentos (nos clientes) não 
devidamente treinada; e falta de mão de obra qualificada no mercado de trabalho.

Quanto às questóes de pesquisa apresentadas no início do artigo, pode-se afirmar, a partir dos resultados encontrados, que nem todas as empresas da indústria de alimentos exigem que seus fornecedores tenham um Sistema de Gestão da Qualidade, mas prezam pela qualidade dos produtos, principalmente em relaçáo ao acabamento sanitário e um pronto atendimento da assistência técnica. Cabe à indústria de equipamentos, motivada pela exigência de outros setores, ou com uma visão de longo prazo, compreender os benefícios que podem ser alcançados com a implantação de um SGQ, se preparando para atender ao mercado interno, cada vez mais exigente, e aumentar a capacidade de exportação.

A maioria das empresas possui procedimentos e registros da qualidade, sem, necessariamente, serem certificadas. As empresas que os possuem, seguem a norma ISO 9001 como modelo. Grande parte das empresas preza por um bom relacionamento com o cliente, instalando o equipamento e prestando treinamento aos futuros usuários. As ferramentas e métodos de apoio à Gestão da Qualidade, apesar dos representantes declararem conhecê-las, são pouco utilizadas e indicadores de desempenho em qualidade também são pouco utilizados.

Muitas empresas alegam dificuldade em substituir a máo de obra que se aposenta ou que troca de emprego. É necessário que essas empresas desenvolvam, em conjunto com entidades empresarias do setor, ações e diretrizes junto a centros formadores de mão de obra para tentar minimizar este problema, procurando, de alguma forma, influenciar e participar na formação de futuros profissionais.

Pode-se apontar como principais limitaçóes desta pesquisa:

- - a forma de coleta de dados: apesar da entrevista pessoal garantir a resposta imediata ao questionário, o entrevistador, algumas vezes, sem perceber, pode inibir ou influenciar o entrevistado;

- - o formato estruturado do questionário: questóes fechadas facilitam a comparaçáo dos resultados entre os respondentes, mas pode induzir algumas respostas. Por isso, a importância de se perguntar uma mesma questão de diversas maneiras;
- - o tamanho da amostra, que limitou a aplicação de alguns testes estatísticos, como a análise fatorial.

- Como proposta de continuidade e desdobramento deste trabalho, sugere-se:

- - a replicaçáo deste survey na forma de uma websurvey com o propósito de atingir um maior número de empresas participantes;

- - uma pesquisa de campo mais aprofundada, por meio de estudo de casos, em empresas previamente selecionadas, que mostrem características peculiares, identificadas neste survey;

- - a replicaçáo de estudos semelhantes em outros setores de bens de capital, para identificação de diferenças e semelhanças;

- - aplicação de um estudo semelhante em indústrias de alimentos, procurando entender os parâmetros de Gestão da Qualidade por ela avaliados na escolha de um fornecedor de equipamentos, para complementar e confrontar com os resultados obtidos nesta pesquisa;

- - o reaproveitamento deste questionário ou de outros já utilizados, com devidos ajustes para aperfeiçoamento do instrumento de pesquisa, para posterior comparação de novos resultados encontrados com outros já publicados.

\section{REFERÊNCIAS}

Alem, A. C. \& Pessoa, R. M. (2005, Setembro), 'O setor de bens de capital e o desenvolvimento econômico: quais são os desafios?', BNDES Setorial, vol. 22, pp. 71-88.

Associação Brasileira da Indústria de Máquinas e Equipamentos. (2007). Disponível em: <http:// www.abimaq.org.br>. Acesso em: 27 mar. 2007.

Avellar, A. P. (2008), Relatório setorial final: bens de capital. Pesquisa DPP - Diretório de Pesquisa Privada. Disponível em: <http://www.finep.gov. br/PortalDPP $>$. Acesso em: 25 mar. 2008.

Battikha, M. G. (2003), 'Quality management practice in highway construction', International Journal of Quality \& Reliability Management, vol. 20, no. 5, pp. 532-550. 
Belga, I. M. F. (2007), Processo de integração e implementação de sistemas de gestão da qualidade, do meio-ambiente e de segurança e saúde ocupacional. Dissertaçáo de mestrado, Pontífica Universidade Católica do Rio de Janeiro, Rio de Janeiro, RJ.

Borrás, M. A. A., \& Toledo, J. C. (2007, Setembro-Dezembro), 'Coordenação da qualidade: proposta de estrutura e método para cadeias de produção agroalimentares', Produção, vol. 17, no. 3, pp. 471-485.

Carvalho, M. M., \& Paladini, E.P. (2006), Gestão da Qualidade: teoria e casos, Campus, Rio de Janeiro.

Couto Jr., C. G. C., \& Galdi, F. C. (2012, Setembro-Outubro), 'Avaliação de empresas por múltiplos aplicados em empresas agrupadas com análise de cluster', Revista de Administração Mackenzie, vol. 13, no. 5, pp. 135-170.

Crosby, P. B. (1994). Qualidade é investimento, 6a ed., José Olympio, Rio de Janeiro.

Domingues, S. A., \& Furtado, A. T. (2003), 'A reflection on the technological activities of the food sector', Proceedings of the forth International Conference on Agri-Food Chain/ Networks Economics and Management, Ribeirão Preto.

Eckes, G. (2001), A revolução seis sigma, 4a ed., Campus, São Paulo.

Feigenbaum, A. V. (1994), Controle da Qualidade Total, vol. 1, Makron Books, São Paulo.

Ferreira, J. J. A. (2005), 'Modelos normalizados de sistema de gestão. Conceitos e certificação: ISO 9001; ISO 14001 e TS16949' in Gestão da Qualidade: teoria e casos, coord. M. M. Carvalho $\&$ E. P. Paladini, Elsevier, Rio de Janeiro, pp. 153186.

Forza, C. (2002), 'Survey research in operations management: a process-based perspective', International Journal of Operations \& Production Management, vol. 22, no. 2, pp. 152-194.

Freitas, H., Oliveira, M., Saccol, A. Z. \& Moscarola, J. (2000, Julho-Setembro), 'O método de pesquisa survey', Revista de Administração, vol. 35, no. 3, pp. 105-112.

Garvin, D. A. (1992), Gerenciando a qualidade: a visão estratégica e competitiva. Qualitymark, Rio de Janeiro.

Ghobril, A. N., \& Moori, R. G. (2009, Janeiro-Abril), 'Alinhamento estratégico entre indústrias de bens de capital e de alimentos: uma análise com base em Miles \&Snow', Gestão \& Regionalidade, vol. 25, no. 73, pp. 6-20.

Hair Jr, J. F., Anderson, R. E., Tatham, R. L., \& Black, W. C. (2005), Análise multivariada de dados, 5 a ed., Bookman, Porto Alegre.

Instituto de Estudos para o Desenvolvimento Industrial (2008), Análise IEDI. Disponível em: http://www.iedi.org.br/cgi/cgilua.exe/sys/start. htm? $1=145 \&$ sid=73\&infoid $=3476$ Acesso em: 08 ago. 2008.

Juran, J. M., \& Gryna, F. M. (1991), Controle da qualidade: handbook - conceitos, políticas e filosofia da qualidade, Makron/McGraw-Hill, São Paulo.

Lagrosen, S. (2007), 'Quality management and environment: exploring the connections', International Journal of Quality \& Reliability Management, vol. 24, no. 4, pp. 333-346.

Lakatos, E. M., \& Marconi, M. A. (1995), 'Pesquisa'. In Fundamentos da metodologia cientifica, 3a ed., org. E. M. Lakatos \& M. A. Marconi, Atlas, São Paulo, pp.155-172.

Malhotra, N. K. (2001), Pesquisa de marketing: uma orientação aplicada, 3a ed., Bookman, Porto Alegre.

Ministério do Desenvolvimento, Indústria e Comércio exterior (2007). Disponível em: http:// www.desenvolvimento.gov.br. Acesso em: 27 Mar. 2007.

Montgomery, D. C., \& Runger, G. C. (2009), Estatística aplicada e probabilidade para engenheiros, 4 a ed., LTC, Rio de Janeiro.

Morettin, P. A., \& Bussab, W. O. (2004). Estatis- 
tica básica, 5a ed., Saraiva, São Paulo.

Pinsonneault, A., \& Kraemer, K. L. (1993), 'Survey research methodology in management information systems: an assessment', Journal of Management Information Systems, vol. 10, no. 2, pp. 75-105.

Rea, L. M., \& Parker, R. A. (2002). Metodologia de pesquisa: do planejamento à execução, Pioneira Thomson Learning, São Paulo.

Sampaio, P.; Saraiva, P., \& Rodrigues, A. G. (2009), 'ISO 9001 certification research: questions, answers and approaches', International Journal of Quality \& Reliability Management, vol. 26, no. 1, pp. 38-58.

Sampieri, R. H., Collado, C. F., \& Lucio, P. B. (1997), Metodología de La Investigación, Mc Graw Hill, México.

Scalco, A. R. (1999), Diagnóstico, análise e proposiçôes para a gestão da qualidade na agroindústria de laticinios do Estado de São Paulo. Dissertação de mestrado, Universidade Federal de São Carlos, São Carlos, SP.
Toledo, J. C., \& Carpinetti, L. C. (2000), 'Gestão da qualidade' in A fábrica do futuro, org. J. C. Toledo \& L. C. Carpinetti, Ed. Banas, NUMA, cap. 13.

Valença, A. C. V. (2001, Setembro), 'A indústria de máquinas e equipamentos para o setor de celulose e papel', BNDES Setorial, vol. 14, pp. 93110.

Vermulm, R. (2003), A indústria de bens de capital seriados, CEPAL (Comissão Econômica para a América Latina e o Caribe - Escritório do Brasil). Disponível em: <http://www.eclac.org/publicaciones/xml/4/21524/LCBRS147RobertoVermulm.pdf>. Acesso em: 24 mar. 2007.

Vermulm, R., \& Erber, F. (2002), Estudo da competitividade de cadeias integradas no Brasil: impactos das zonas de livre comércio, Cadeia: bens de capital. NEIT/Unicamp, Campinas. 80 p. (nota técnica final). 